\title{
Erratum to: Temperature and human thermal comfort effects of street trees across three contrasting street canyon environments
}

\author{
Andrew M. Coutts ${ }^{1,2}$ • Emma C. White ${ }^{1}$ - Nigel J. Tapper ${ }^{1,2}$. \\ Jason Beringer $^{3} \cdot$ Stephen J. Livesley $^{4}$
}

Published online: 25 May 2016

(C) Springer-Verlag Wien 2016

\section{Erratum to: Theor Appl Climatol}

DOI 10.1007/s00704-015-1409-y

In Coutts et al. (2015), regarding the equation for calculating mean radiant temperature $\left(t_{m r t}\right)$ using the black globe thermometers, a typographical error was made during the manuscript editing process. The equation should read:

$t_{m r t}=\sqrt[4]{\left(t_{\mathrm{g}}+273.15\right)^{4}+\frac{h_{C_{\mathrm{g}}}}{\varepsilon d_{\mathrm{g}}^{0.4}}\left(t_{\mathrm{g}}-t_{a}\right)}-273.15$

The online version of the original article can be found at http://dx.doi.org/ 10.1007/s00704-015-1409-y.

Andrew M. Coutts

Andrew.Coutts@monash.edu

1 School of Earth, Atmosphere and Environment, Monash University, Building 28, Wellington Rd, Clayton, VIC 3800, Australia

2 CRC for Water Sensitive Cities, Clayton, VIC 3800, Australia

3 School of Earth and Environment, The University of Western Australia, Crawley, VIC 6009, Australia

4 Department of Resource Management and Geography, The University of Melbourne, Melbourne, VIC 3121, Australia

All terms are defined in Coutts et al. (2015). The error was typographical and does not affect the paper content or findings. 